Reflections and Conjectures*

\section{Open Scholarly Publishing and Knowledge Mobilization: Combining Two Initiatives to Achieve Social Impact}

\author{
Julie Bayley \\ University of Lincoln \\ David Phipps \\ York University \\ Tony Roche \& Steve Lodge \\ Emerald Publishing
}

Scholarly and Research

Communication

VOLUME 12 / ISSUE 1 / 2021

\begin{abstract}
Trends within universities and scholarly publishers are converging to develop tools and services to maximize the societal impacts of research. The open research agenda underpins drives to improve accessibility to knowledge, while the academic community is increasingly tasked to generate "impact" on society. With obvious synergies between these agendas, it is increasingly important for collaboration across the research ecosystem to build on this complementarity. This article reflects on, and conjects a future for, academic-publisher collaborations to connect these agendas.
\end{abstract}

Keywords: knowledge mobilization, research impact, scholarly publishing, open research

\section{Résumé}

Les tendances au sein des universités et des éditeurs savants convergent pour développer des outils et des services permettant de maximiser les impacts sociétaux de la recherche. L'agenda de la recherche de libre accès sous-tend les efforts visant à améliorer l'accessibilité aux connaissances, tandis que la communauté universitaire est de plus en plus chargée de générer un "impact » sur la société. Compte tenu des synergies évidentes entre ces agendas, il est de plus en plus important que la collaboration au sein de l'écosystème de la recherche s'appuie sur cette complémentarité. Cet article est le fruit d'une réflexion et d'une conjecture sur l'avenir des collaborations entre les universités et les éditeurs afin de relier ces agendas. Il est rédigé conjointement par un gestionnaire de l'impact de la recherche et un chercheur universitaire (Bayley), un praticien de la mobilisation des connaissances universitaire (Phipps) et des collègues d'Emerald Publishing (Roche et Lodge).

Mots clés : mobilisation des connaissances, impact de la recherche, publication académique, recherche ouverte

* Please see Editorial: Syntheses, Reflections, and Conjectures in Scholarly and Research Communication: $S R C^{1+1}$

Bayley, Julie, Phipps, David, Roche, Tony, \& Lodge, Steve. (2021). Reflections and Conjectures Open Scholarly Publishing and Knowledge Mobilization: Combining Two Initiatives to Achieve Social Impact. Scholarly and Research Communication, 12(1), 13 pp. doi:10.22230/src.2021v12n1a391
Julie Bayley is Director of Research Impact Development at the University of Lincoln, Research and Enterprise. Email: jbayley@lincoln.ac.uk

David Phipps is Assistant Vice President, Research Strategy and Impact, at York University. Email: dphipps@yorku.ca

Tony Roche is Director of Publishing \& Strategic Relationships at Emerald Publishing, Howard House.

Email: troche@emerald.com

Steve Lodge is Head of Services at Emerald Publishing, Howard House. Email: slodge@emerald.com 


\section{Scholarly and Research}

\section{Communication}

VOLUME 12 / ISSUE 1 / 2021
Our story starts ...

Edinburgh, Scotland. The Royal College of Surgeons in April 2015, the day after the first U.K. Knowledge Mobilization (sorry, Mobilisation) Forum. A meeting of the Association of Research Managers and Administrators Impact Special Interest Group, comprising mainly impact officers - the collectively named staff with a variety of job titles, many on short-term contracts-who administered the first ever postsecondary system-wide impact assessment in the U.K. Author David Phipps is heading up the stairs and (almost literally) bumps into author Julie Bayley, who is heading down. A series of polite Canadian/British apologies occur, during which there is a simultaneous (and audible "ooh") epiphany that the other is in fact the real-life incarnation of their impact Twitter soulmate. Thus ensued squeals of delight, hugs, and the (still occurring) waving of jazz hands.

This informal starting point began a continuing professional collaboration that, through the opportunity to compare research impact approaches internationally, has led to a body of work on individually and institutionally healthier approaches to impact (more on that later). This collaboration has included a fellowship from the Association of Commonwealth Universities and work in Canada, the U.K., the U.S., Flanders (Belgium), Denmark, Spain, Italy, Australia, New Zealand, Iran, and Singapore. Along the way, and reflected in this conjecture on the future of research impact, we have enjoyed collaborations with the Social Sciences and Humanities Research Council of Canada (SSHRC), the Networks of Centres of Excellence of Canada, Kids Brain Health Network (Canada), the National Institute for Health Research (U.K.), and Emerald Publishing.

The relationship between academia and publishers has not always been straightforward. Tensions, both historically and currently, arise most routinely from distaste around profit models, with critics arguing this results in unequal and power-imbalanced relationships, seeding frustration and distrust (Beverungen, Böhm, \& Land, 2012). While a discussion of the depth and complexity of these issues is beyond the scope of this article, a wealth of critical literature explores these issues (e.g., Gadd, Oppenheim, \& Probets, 2003; Lämmerhirt, Gray, Lawson, \& Moore, 2016; Larivière, Haustein, \& Mongeon, 2015; Lawson, Sanders, \& Smith, 2015; Pooley, 2020). In this article-and in full recognition of these tensions-Phipps and Bayley reflect on their experience of working in partnership with Tony Roche and Steve Lodge from a commercial publisher, Emerald Publishing, to drive impact.

Through this, and our wider scholarly and developmental activities within and beyond social sciences and humanities, we present a conjecture about how to engender a more collaborative and embedded approach to impact, drawing publishers and academia more closely together on shared interests. This article is not a research or methodological piece; it is a set of reflections grounded in literature, academic scholarship, and professional practice that offers our observations about the converging trends in knowledge mobilization, research impact, and open publishing. Reflecting on impact, the contribution of open publishing and open science, and the experiences of an academicpublisher partnership, we consider how current signals of improved practice and improved academic-publisher relationships can evolve to enable the future of research impact.

Bayley, Julie, Phipps, David, Roche, Tony, \& Lodge, Steve. (2021). Reflections and Conjectures Open Scholarly Publishing and Knowledge Mobilization: Combining Two Initiatives to Achieve Social Impact. Scholarly and Research Communication, 12(1). doi:10.22230/src.2021v12n1a391 


\section{Knowledge mobilization and research impact in universities}

To imagine the future, we must first understand the past and present. Knowledge brokering - the act of connecting and creating relationships between producers and users of knowledge-is not new. Jonathan Lomas (2007) reports that relationships between academic researchers and non-academic research partners can be documented as far back as 1880 , giving the example that the dominance of the German dye industry was predicated (at least in part) on networks of academic and industrial partners.

In the United States of America, the 1862 Land Grant Act, or Morrill Act, grants federal lands for use by states to create colleges of agriculture and engineering. By ensuring that research at the land-grant universities was made available to benefit local farmers and agricultural industries, it began the U.S. federal government's entry into education for economic purposes. The Morrill Act "was not primarily a piece of educational legislation. Rather, it was an important piece of economic policy" (Key, 1996, p.198). Continuing in the U.S., the passage of the Bayh-Dole Act in 1981 heralded the expansion of academic technology transfer (also known as commercialization, and commonly referred to as knowledge transfer in the U.K.). Although universities and industry have always collaborated, and technology licencing preceded the Bayh-Dole Act, the Act created the expectation that universities receiving federal funds for research were expected to make efforts to commercialize the research through patenting, licencing, and more recently, entrepreneurship and company creation. However, this is not without its controversy, and empirical research has demonstrated that the rush to patent in a post-Bayh Dole university has resulted in patents of less quality than those universities filing and licencing patents before Bayh Dole (Mowery, Nelson, Sampat, \& Ziedonis, 2001).

Within the U.K., while research councils have, until early 2020 (Bayley, 2020), required applicants to describe their pathway to social impact, or "impact" for short, for many years the research impact landscape has arguably been dominated by the Research Excellence Framework (REF). The policy development that ultimately led to the inclusion of impact in this U.K. research assessment exercise has been described as a fourphased iterative development, with the U.K. and Australia both considering models of impact assessment (Williams \& Grant, 2018). Impact was first introduced into the ongoing series of national U.K. research assessments in 2011 for the 2014 assessment cycle to supplement evaluations that were previously centred on outputs and research environment alone (Research Excellence Framework, 2020). Its introduction heralded a new era of financially weighted institutional accountability for social benefits, with results materially affecting approximately $£ 2$ billion of government funding awarded. For the 2021 REF cycle, with a deadline for submissions of March 31, 2021, the proportion of funding dependent on impact increased from 20 percent in 2014 to 25 percent, paying testament to the deepening expectations of the application of research in the "real world."

There is no such formal impact assessment in Canada, with the growth of knowledge mobilization/translation instead driven primarily by research funding agencies. The Networks of Centres of Excellence (Government of Canada, 2019) program was founded in 1989 as a collaboration of the three federal funding agencies to support

Bayley, Julie, Phipps, David, Roche, Tony, \& Lodge, Steve. (2021). Reflections and Conjectures Open Scholarly Publishing and Knowledge Mobilization: Combining Two Initiatives to Achieve Social Impact. Scholarly and Research Communication, 12(1). doi:10.22230/src.2021v12n1a391 


\section{Scholarly and Research}

\section{Communication}

VOLUME 12 / ISSUE 1 / 2021 "research, commercialization and knowledge translation" (para. 1). The Canadian Health Services Research Foundation (now Healthcare Excellence Canada, 2020) was created in 1996 with a mandate "to support evidence-informed decision-making, management and delivery of health services through funding research, capacity building and knowledge transfer" (para. 2). The Canadian Institutes of Health Research adopted a knowledge translation mandate through the Canadian Institutes of Health Research Act in 2000 (Government of Canada, 2021), and SSHRC included knowledge mobilization as a mandatory element in all grant applications as part of the "connections" theme of the revised program architecture as of 2009 (Government of Canada, 2013). The growth in knowledge mobilization requirements by Canadian funders drove a few universities to mirror ubiquitous supports for technology transfer with institutional supports for knowledge mobilization (such as the Memorial University of Newfoundland's Harris Centre and York University's Knowledge Mobilization Unit, both founded in 2006). Research Impact Canada is another relevant initiative, representing a network of 21 universities dedicated to building institutional capacity for knowledge mobilization and maximizing the non-commercial impacts of research.

The REF's powerful presence in U.K. universities has become perhaps the most prominent example of a formally operationalized "impact agenda," such that it has become a standard of comparison for other national research impact assessment systems (Wróblewska, 2021). The need to do well in the REF, along with the challenges of introducing a new agenda into an already pressured higher education system, has led perhaps unsurprisingly to an upspring of new private sector service providers filling (or expanding) functions traditionally located within university research offices. Examples include impact information management systems, case study authorship, channels for non-academic communications, and evidence gathering. In part, these reflect pragmatic responses to capacity limitations within universities by external providers, while also underlining a shift toward an ecosystem approach to impact.

\section{A call for impact literacy}

The REF and impact are not synonymous (Smith, Bandola-Gill, Meer, Stewart, \& Watermeyer, 2020), but imbuing impact with financial consequences through assessment risks continually conflating the two. In response to a growing concern about the commodification of impact, Bayley and Phipps (2019a) built the concept of "impact literacy." Impact literacy is the combination of knowing how to create impacts using knowledge mobilization methods, identifying what impacts can or have occurred, and outlining the skills needed by those who are involved in generating change. An extension of this work in a follow-up paper (Bayley \& Phipps, 2019b) rooted this triadic approach in understanding why impact was needed, along with expressing parallel paths for individual and institutional literacy. The fundamental tenets for this work are that enabling people to understand impact equips the sector with the ability to develop healthy approaches to impact unbound by assessment rhetoric.

\section{The role of publishers in contributing to impact}

The publishing sector is a key part of the research ecosystem. In the two decades from 1996-2017, global research and development grew by around 250 percent, with similar increases in the number of researchers, patents, and journal articles published (OSI,

Bayley, Julie, Phipps, David, Roche, Tony, \& Lodge, Steve. (2021). Reflections and Conjectures Open Scholarly Publishing and Knowledge Mobilization: Combining Two Initiatives to Achieve Social Impact. Scholarly and Research Communication, 12(1). doi:10.22230/src.2021v12n1a391 
2019). Research as a global endeavour continues to place huge emphasis on publication in scholarly journals and monographs, with obligations to publish largely standing unaffected by incoming drives for social connectivity and collaboration with partners beyond the academy. Academic publications have always held significant currency for academic progression and reputation, and they have arguably become even more potent in assessment-driven systems that confer reputational advantage to those publishing in the highest-quality, most-prestigious venues.

However, while publications are a fundamental component of research practice, the research community is increasingly questioning the relevance of the traditional citationoriented metric, the journal impact factor (Callaway, 2016), and is converging on the need for more equitable and responsible indicators of research quality and individual contribution (Wilsdon, Bar-Ilan, Frodeman, Lex, Peters, \& Wouters, 2017). More profoundly for knowledge mobilization, impact, by definition, sits beyond both scholarly outputs and the traditional markers of influence (such as citations). Thus it is essential to go beyond scholarly dissemination to amplify research messages and revisit the relationship between academics, publishers, and social change. While research evaluation itself is evolving, there is increasing awareness that the greater the access to research, the greater the opportunity for research itself to contribute to change in society, on any scale (Tennant, Waldner, Jacques, Masuzzo, Collister, \& Hartgerink, 2016). What remains unexplored, however, is the role of the publisher as a collaborator in academic impact, beyond providing a mechanism for the dissemination of scholarly information.

\section{Open as a step toward impact}

Practically, the key contribution of publishers to impact is the creation of content digestible by, and accessible to, potential users. Paramount in the shifting sands from journal-bound traditions to widened access to knowledge is the acceleration of open research. Open access has no single, universally adopted definition, but in the scholarly publication space it is broadly accepted as referring to access to research literature that is digital, online, free to use, and free of most copyright and licencing restrictions (Suber, 2004). Furthermore, open science/open research extends to include underpinning research assets such as data, the aim being to support transparency, reproducibility, and reuse. A recent example of innovation in the provision of open science/research tools is the Open Science Framework, an open source software project from the Center for Open Science (n.d.-a) that facilitates open collaboration in science research.

The volume of open access publications across scholarly publishing has grown steadily in recent years and is accelerating, with around 55 percent of global output being classified as available open access by 2018 (the exact percentage varying by country, discipline, domain, academic career stage, and the type of open measured) (Archambault, Amyot, Deschamps, Nicol, Provencher, Rebout, \& Roberge, 2014). Indeed, open access output exceeded subscription output for the first time in 2020 (Hook, 2021). In addition, the "citation advantage" of open access publications is also well established. A recent survey on attitudes to open (Emerald, 2020) revealed a significant attitudinal shift, with the number of researchers considering publishing open access and sharing links to supporting datasets increasing from 29 percent in 2019 to 51 percent in 2020. However, while improving visibility and the likelihood of reuse (impact) is a primary reason researchers

Bayley, Julie, Phipps, David, Roche, Tony, \& Lodge, Steve. (2021). Reflections and Conjectures Open Scholarly Publishing and Knowledge Mobilization: Combining Two Initiatives to Achieve Social Impact. Scholarly and Research Communication, 12(1). doi:10.22230/src.2021v12n1a391 


\section{Scholarly and Research}

\section{Communication}

VOLUME 12 / ISSUE 1 / 2021 choose to publish open (Wiley, 2017), journal impact factors and reputation remain one factor in where to publish (Taylor \& Francis Group, 2019). However, when controlling for discipline, the age of the journal, and geographic location, the differences in citations for articles in subscriptions journals are essentially the same as for those in open access journals (Bjork \& Solomon, 2012). Open access non-commercial journals are increasingly supported by online journal management and publishing platforms such as Open Journal Systems (Edgar \& Willinsky, 2010), and arguments are made that they reflect the original nature of scholarly communications as a public good (Fuchs \& Sandoval, 2013). As publishers variously sign up to standards such as Open Science Framework's Transparency and Openness Promotion (TOP) guidelines (Center for Open Science, n.d.-b) and the United Nations (2020) Sustainable Development Goals Publishers Compact, and with varied practice on the tightening or flexing of green open access and embargo restrictions, there is a timeliness at looking how to harness this growing drive to "open" to strengthen pathways to impact.

The global COVID-19 pandemic has undoubtedly accelerated open at an unprecedented rate. The need for rapid access to COVID-19-related material has led to research being processed far more swiftly, made available without paywall, and/or posted prior to peer review on pre-print servers such as medRxiv and bioRxiv. While open and immediate access to the latest research on COVID-19 is largely seen as essential in the fight against the pandemic, the debate continues regarding the relative value and perceived risks of pre-publication peer review versus unvalidated but rapidly published pre-prints (Maslove, 2018). This unprecedented era has doubtless highlighted the benefit of open, but the sector has yet to establish how to take practices borne of such pressure into sustainable future practice.

\section{Joining forces to develop tools for impact}

Open access may be a welcome shift in knowledge communication, but it is not in itself a sufficient mechanism to drive research impact. Increased accessibility offers the possibility of - and an ethical commitment to-the public use of research, but for impact, knowledge mobilization must be active. That is, it is not enough to simply make research available, as this relies solely on public energies to find it and translate its utility. Instead, availability should be considered the first necessary step for impact, demanding, then, more connected thinking about how to elevate this to use.

It is within this nexus that Bayley and Phipps began a collaboration with Emerald Publishing, seeking to jointly harness the learning that led to the impact literacy framework and the strategic focus and broadcast channels of Emerald. This collaboration was initiated by Emerald, with an express wish to understand, from academic and research management voices within the sector, how to support impact as an applied publisher. Considerable time was taken at the outset to establish clarity on what impact is, particularly decoupling it from more traditional notions of academic impact (e.g., citations) and rooting discussions in an understanding of the additional pressures that requirements for impact bring to bear on academics. Drawing on these insights and the impact literacy work, this partnership first yielded an Impact Literacy Workbook (see Table 1) to support researchers in building an impact plan. 
The Impact Literacy Workbook is a guide and tool for planning an impact strategy in a grant application including sections to help researchers:

1) Framing the problem (e.g., high rates of teenage pregnancy)

2) Framing the impact (e.g., lower rates of teenage pregnancy)

3) Identifying indicators and evidence (e.g., government policy/statistics showing current rates)

4) Identifying stakeholders and beneficiaries (e.g., young people, clinic staff, parents, teachers)

5) Co-producing impact (e.g., academic researchers working with partners from the public, private, or nonprofit sectors)

6) Mobilizing your knowledge (e.g., use methods to enhance the reach of research evidence and their associated outputs)

7) Challenges and facilitators (e.g., sensitive topics, differing views, hard-toaccess key groups)

By answering questions for each section, the Impact Literacy Workbook allows a researcher to assemble the elements of an impact plan into a one-page impact summary canvas.

Source: Bayley \& Phipps, $2019 \mathrm{C}$

Crucially, alongside activities to develop (and interactively redevelop) the impact literacy tool, conversations extended into a) the ethical aspects of impact and b) reflections on the day-to-day difficulties faced by many in "doing impact." More bluntly, without parallel attention to institutional support for impact, the benefits of supporting individuals could be muted or even lost. This led to two further redevelopments: an extended impact literacy framework comprising purpose, mission, and ethics (e.g., why), including a new institutional dimension (Bayley \& Phipps, 2019b), and a new Institutional Healthcheck Workbook to support organizations in self-assessing their readiness for impact. The five categories of institutional health for assessment are shown in Table 2.

\section{Table 2: Institutional health check categories}

1. Commitment: Is the organization committed to impact (e.g., strategy, systems, staff)?

2. Clarity: Do academic and non-academic staff understand impact, expectations, roles?

3. Connectivity: Do the organizational units work together, connect to strategy, act cohesively?

4. Co-production: Is there advice, training, support to develop skills for impact?

5. Competencies: What is the extent and quality of engagement with non-academic stakeholders?

Source: Bayley \& Phipps, 2019d

\section{Combining developments in publishing and knowledge mobilization to achieve social impact}

The development of two tools, and associated scholarly outputs, and commentaries on the benefits of open access and open publishing to research uptake and impact do not represent game-changing innovations; together with the resulting academic-publisher 


\section{Scholarly and Research}

\section{Communication}

VOLUME 12 / ISSUE 1 / 2021 collaboration, however, they do point to a potential future of scholarly communications. The partnership activities outlined here, situated within the sometimes tense relationship between academia and publisher, signal optimism for more connection among participants in the research ecosystem. More specifically, this work reflects the value of publishers connecting into the impact pathway and listening to those within the academic sphere, rather than presuming to know or assuming the proverbial "job is done" at the point of publication.

Further, it is important to note that not only do publishers have a significant role to play in mobilizing research to potential users, they are also key in connecting impact practitioners with the growing evidence base for implementation science. Stephen MacGregor, David Phipps, Cathy Malcolm Edwards, Jen Kyffin, and Virginie Portes (2021) recently reflected on the future(s) of knowledge mobilization in Canada, including predictions about the increased integration of impact into the research enterprise, the internationalization of impact scholarship and practice, and increased collaborations between impact researchers and impact practitioners. The latter is important since, as Alison Powell, Huw Davies, and Sandra Nutley (2017) state, "there is the ironic situation that the field of knowledge mobilisation practice seems somewhat detached from its own knowledge base, with knowledge mobilisation activities often being developed and carried out without reference to the existing theory or to practical experience, and without the robust evaluations that could contribute to the knowledge base for the future" (p. 217).

Closing the loop between research, research users, impact scholarship, and impact practice is essential for addressing the needs of society, and it is at this point publishers have a pivotal role. Moreover, strengthening and embedding impact requires actions from academics and publishers far beyond the development of stand-alone tools.

For academia there are numerous developmental opportunities, including

1. The recognition of impact in academic career advancement

In countries where there are formal tenure and promotion policies, such as Canada, many such policies include public and community engagement as eligibility requirements for tenure decisions. However, the local implementation of those policies is not consistent, and departmental review committees tend to prioritize traditional scholarly outputs (Barreno, Elliott, Madeuka, \& Sarny, 2013). In countries such as the U.K., impact has high currency through activities connected to the REF, but there are unstandardized expectations for impact in career progression. For this to change, engaged scholarship and research impact not only need to be a valued part of progression criteria, but reviewers need to be trained to recognize and reward good, healthy, and literate contributions to social change.

2. Institutional impact literacy and healthy practices

Funders expect researchers to plan for impact, and university mission statements routinely reflect a commitment to having a positive impact on local and global communities. However, such expectations of researchers cannot be achieved by

Bayley, Julie, Phipps, David, Roche, Tony, \& Lodge, Steve. (2021). Reflections and Conjectures Open Scholarly Publishing and Knowledge Mobilization: Combining Two Initiatives to Achieve Social Impact. Scholarly and Research Communication, 12(1). doi:10.22230/src.2021v12n1a391 
individual competency alone. They require institutional commitment and resources to embed institutional impact literacy (Bayley \& Phipps, 2019b). In line with institutions' routine investments in infrastructure for commercialization and technology transfer, similar substantive support for co-production between academic and non-academic partners (Hoekstra, Mrklas, Khan, McKay, Vis-Dunbar, Sibley, Nguyen, Graham, Guiding Principles Consensus Panel, \& Gainforth, 2020; Reed, Robson, Lindgren, Friedrichsen, Brock, Davidson-Hunt, Lichtenstein, Shackleton, Vassuer, \& Worthen, 2020) and configuring effective impact processes within the organization appear necessary.

3. The profession of research impact analysis and practice

In 2007, Sandra Nutley, Isobel Walter, and Huw T.O. Davies (2007) reflected that systems of impact such as networks and communities of practice were in the future. Thirteen years later, that future is emerging, but it has not yet fully matured. Associations for research impact, such as Research Impact Canada and the Association of Research Managers and Administrators Impact Special Interest Group in the U.K., demonstrate growing communities of practice. However, globally, such networks are arguably less fully formed than their techtransfer (commercial) forebears, such as the international Association of University Technology Managers and PraxisAuril in the U.K.

On the publishing side, several approaches to maximizing the opportunity of the impact convergence between scholarly publishing and academic research would be useful:

1. A broadened business focus beyond bibliometric data

Traditional foci on bibliometric data reflects only influence within academic circles, demanding shifts not only to social/altmetric coverage (demonstrating wider attention) but also to indicators of uptake. With a pivotal role in broadcasting research, publishers are well placed to strategically extend support to researchers to engage with, and mobilize knowledge to, stakeholders in pursuit of real, measurable societal change.

2. Investment in tools and training to develop impact literacy for publishing staff

Bringing impact more centrally into the publishing domain requires a mindset and skill set shift for those working within the industry away from traditional (bibliometric) measures of success. An organization-wide shift toward social impact (such as that outlined in point 1) requires staff development, particularly in understanding not only how impact is achieved but how it fits within the broader academic landscape. Publishing staff will also benefit from developing competencies for broader research impact, including knowledge brokering between researchers and societal stakeholders (Bayley, Phipps, Batac, \& Stevens, 2018). Additionally, publishers will need to invest in new technologies to support data beyond publications, citations, and bibliometrics.

3. Collaborative development with academia

To strengthen the joint content, utility, and acceptability of tools in support of impact literacy, these must be co-built with researchers, research managers, and

Bayley, Julie, Phipps, David, Roche, Tony, \& Lodge, Steve. (2021). Reflections and Conjectures Open Scholarly Publishing and Knowledge Mobilization: Combining Two Initiatives to Achieve Social Impact. Scholarly and Research Communication, 12(1). doi:10.22230/src.2021v12n1a391 


\section{Scholarly and Research}

\section{Communication}

VOLUME 12 / ISSUE 1 / 2021 librarians. The successful design of systems and tools to support broader societal impacts needs to be based on sound knowledge mobilization principles of stakeholder engagement and the co-creation of new products and services that meet the needs of publishers as well as academic and non-academic stakeholders.

\section{Conclusion: Aligning the research-to-impact ecosystem}

For those publishers whose vision is for research to generate tangible social benefit, the entwined open and impact movements need dual attention. These two movements have arisen in parallel and were never designed for the same purpose; therefore, it is incumbent on all those in the research community to draw them meaningfully together. Simply extending traditional models of publishing only offers platitudes for impact. Just as impact arguably gives research a "purpose," competing challenges within this research ecosystem bring pressures that inhibit the achievement of open and impact aspirations. Change is dependent on recognizing and addressing these barriers, and involving the whole ecosystem is essential.

Across this research-to-impact ecosystem, the need to drive the development of knowledge remains paramount. However, governments will continue to invest in challengedriven research to help address long-standing societal issues. Many such issues are in the realm of the social sciences and humanities, including growing economic and social inequities, homelessness, migration (voluntary or forced), education, reconciliation with Indigenous peoples, international security, cultural identities, and many more. Accordingly, universities will continue to play a central role in drives toward social change, externally engaging with local and global communities, and internally overseeing academic activity and progression. We hope that engaged scholarship becomes a consistently rewarded activity (as exemplified by 10 case studies profiled by the Declaration on Research Assessment [DORA, 2020]), underpinned by healthy and literate expectations of impact. In parallel, we are optimistic that demonstrations of publishers' commitment to open and impact (such as the 64 current signatories of the SDG Publishers Compact) signifies an upward trajectory of activities to contribute to meaningful and significant social change. It is through this collective action across the research ecosystem that the impacts of research will be fully achieved and recognized. Our conjecture is that connecting academia and publishers operationally in the joint pursuit of impact brings the most promise of making a difference in the future.

\section{Websites}

Association of Research Managers and Administrators Impact Special Interest Group, https://arma.ac.uk/

Association of University Technology Managers, https://autm.net/

bioRxiv, https://www.biorxiv.org/

Emerald Publishing, https://www.emeraldgrouppublishing.com/

Kids Brain Health Network, https://kidsbrainhealth.ca

medRxiv, https://www.medrxiv.org/

National Institute for Health Research, https://www.nihr.ac.uk/

Networks of Centres of Excellence of Canada, https://www.nce-rce.gc.ca/Index_eng.asp

PraxisAuril, https://www.praxisauril.org.uk/

Research Impact Canada, http://www.researchimpact.ca

Bayley, Julie, Phipps, David, Roche, Tony, \& Lodge, Steve. (2021). Reflections and Conjectures Open Scholarly Publishing and Knowledge Mobilization: Combining Two Initiatives to Achieve Social Impact. Scholarly and Research Communication, 12(1). doi:10.22230/src.2021v12n1a391 
SDG Publishers Compact, https://www.un.org/sustainabledevelopment/sdg-publishers-compact/

Social Sciences and Humanities Research Council of Canada, https://www.sshrc-crsh.gc.ca

/home-accueil-eng.aspx

\section{References}

Archambault, Eric, Amyot, Didier, Deschamps, Philippe, Nicol, Aurore, Provencher, Françoise, Rebout, Lise, \& Roberge, Guillaume. (2014). Proportion of open access papers published in peer-reviewed journals at the European and world levels-1996-2013. Digital Commons. Lincoln, NB: University of Nebraska. URL: https://digitalcommons.unl.edu/scholcom/8/ [Accessed June 8, 2021].

Barreno, Leonzo, Elliott, Patricia, Madeuka, Ijeoma, \& Sarny, Dominique. (2013). Community engaged scholarship and faculty assessment: A review of Canadian practices. Regina, SK: University of Regina. URL: https://www.mtroyal.ca/AboutMountRoyal/TeachingLearning/CSLearning I_pdfs/adc_csl_pdf_res_revcanpract.pdf [Accessed June 12, 2021].

Bayley, Julie. (2020). Where the pathway ends: Taking impact off-road [Blog post]. Julie Bayley. URL: https: //juliebayley.blog/2020/02/27/where-the-pathway-ends-taking-impact-off-road/ [March 26, 2021].

Bayley, Julie, \& Phipps, David. (2019a). Building the concept of research impact literacy. Evidence \& Policy, 15(4), 596-606. doi:10.1332/174426417X15034894876108

Bayley, Julie, \& Phipps, David. (2019b). Extending the concept of research impact literacy: Levels of literacy, institutional role and ethical. Emerald Open Research, 1, 1-14. URL: https://emeraldopen research.com/articles/1-14 [June 12, 2021].

Bayley, Julie, \& Phipps, David. (2019c). Impact literacy workbook: Helping you demonstrate the provable effects of your research in the real world. Bingley, UK: Emerald Publishing. URL: https://www .emeraldgrouppublishing.com/sites/default/files/2020-06/Impact\%20Literacy\%20Workbook \%20Final.pdf [June 12, 2021].

Bayley, Julie, \& Phipps, David. (2019d). Institutional healthcheck workbook: Helping you diagnose how healthy your institution is in delivering real change. Bingley, UK: Emerald Publishing. URL: https://www.emeraldgrouppublishing.com/sites/default/files/2020-06/Institutional\%20 Healthcheck\%20Workbook\%20Final.pdf [June 12, 2021].

Bayley, Julie, Phipps, David, Batac, Monica, \& Stevens, Ed. (2018). Development of a framework for knowledge mobilisation and impact competencies. Evidence and Policy, 14(4), 725-738. doi: 10.1332/174426417X14945838375124

Beverungen, Armin, Böhm, Steffan, \& Land, Christopher. (2012). The poverty of journal publishing. Organization, 19(6), 929-938.

Björk, Bo-Critser, \& Solomon, David. (2012). Open access versus subscription journals: A comparison of scientific impact. BMC Medicine, 10, 73. doi:10.1186/1741-7015-10-73

Callaway, Ewan. (2016). Beat it, impact factor! Publishing elite turns against controversial metric. Nature, 535(7611), 210-211. URL: https://www.nature.com/news/beat-it-impact-factor -publishing-elite-turns-against-controversial-metric-1.20224 [March 26, 2021].

Center for Open Science. (n.d.-a). Manage and share your research with OSF - an easy, integrated platform. Charlottesville, VA: Center for Open Science. URL: https://www.cos.io/products/osf [June 12, 2021].

Center for Open Science. (n.d.-b). Transparency and openness promotion guidelines. Charlottesville, VA: Center for Open Science. URL: https://osf.io/9f6gx/ [June 12, 2021].

DORA. (2020). Reimagining academic assessment: Stories of innovation and change. DORA. URL: https://sfdora.org/dora-case-studies/ [June 8, 2021].

Edgar, Brian, \& Willinsky, John. (2010). A survey of the scholarly journals using open journal systems. Scholarly and Research Communication, 1(2), 1-22. URL: https://src-online.ca/index.php/src /article/view/24 [June 12, 2021].

Bayley, Julie, Phipps, David, Roche, Tony, \& Lodge, Steve. (2021). Reflections and Conjectures Open Scholarly Publishing and Knowledge Mobilization: Combining Two Initiatives to Achieve Social Impact. Scholarly and Research Communication, 12(1). doi:10.22230/src.2021v12n1a391
Scholarly and Research

Communication

VOLUME 12 / ISSUE 1 / 2021 


\section{Scholarly and Research Communication}

VOLUME 12 / ISSUE 1 / 2021
Emerald. (2020). Academic culture - is it time for change? [Report]. Bingley, UK: Emerald Publishing. URL: https://www.emeraldgrouppublishing.com/real-impact-newsletter-issue-3 [June 12, 2021].

Fuchs, Christian, \& Sandoval, Marisol. (2013). The diamond model of open access publishing: Why policy makers, scholars, universities, libraries, labour unions and the publishing world need to take non-commercial, non-profit open access serious. TripleC: Communication, Capitalism \& Critique, 11(2), 428-443.

Gadd Elizabeth, Oppenheim, Charles, \& Probets, Steve. (2003). RoMEO studies 1: The impact of copyright ownership on academic author self-archiving. Journal of Documentation, 59(3), 243-277. doi:10.1108/00220410310698239

Government of Canada. (2013). SSHRC news. Ottawa, ON: Social Sciences and Humanities Research Council. URL: https://www.sshrc-crsh.gc.ca/news_room-salle_de_presse/latest_news-nouvelles _recentes/sshrc_news_may_2011-nouvelles_crsh_mai_2011-eng.aspx [June 12, 2021].

Government of Canada. (2019). Networks of Centres of Excellence of Canada. Ottawa, ON: Networks of Centres of Excellence. URL: https://www.nce-rce.gc.ca/About-APropos/History-Histoire_eng.asp [June 12, 2021].

Government of Canada. (2021). Canadian Institutes of Health Research Act. Ottawa, ON: Department of Justice. URL: https://laws.justice.gc.ca/eng/acts/c-18.1/page-1.html [June 12, 2021].

Healthcare Excellence Canada. (2020). Our story. Ottawa, ON: Healthcare Excellence Canada. URL: https://www.cfhi-fcass.ca/about/our-story [March 26, 2021].

Hoekstra, Femke, Mrklas, K.J., Khan, M., McKay, Rhyann C., Vis-Dunbar, M., Sibley, K.M., Nguyen, T., Graham, I.D., Guiding Principles Consensus Panel, \& Gainforth, Heather L. (2020). A review of reviews on principles, strategies, outcomes and impacts of research partnerships approaches: A first step in synthesising the research partnership literature. Health Research Policy \& Systems, 18(1), 51-63. doi:10.1186/s12961-020-0544-9

Key, Scott. (1996). Economics or education: The establishment of American land-grant universities. The Journal of Higher Education, 67(2), 196-220. doi:10.1080/00221546.1996.11780256

Lämmerhirt, Danny, Gray, Jonathan, Lawson, Stuart, \& Moore, Samuel. (2016). PASTEUR4OA: Revealing the true costs of Gold OA - Towards a public data infrastructure of scholarly publishing cost. URL: http://www.pasteur4oa.eu/sites/pasteur4oa/files/resource/Revealingthetruecostsof GoldOA_FINAL.pdf [June 12, 2021].

Larivière, Vincent, Haustein, Steffanie, \& Mongeon, Philippe. (2015). The oligopoly of academic publishers in the digital era. PloS one, 10(6), e0127502.

Lawson, Stuart, Sanders, Kevin, \& Smith, Lauren. (2015). Commodification of the information profession: A critique of higher education under neoliberalism. Journal of Librarianship and Scholarly Communication, 3(1), 1-15 doi:10.7710/2162-3309.1182

Lomas, Jonathan. (2007). The in-between world of knowledge brokering. BMJ, 334(7585), 129-132. doi:10.1136/bmj.39038.593380

MacGregor, Stephen, Phipps, David, Edwards, Cathy, Kyffin, Jenn, \& Portes, Virginie. (2021). Active engagement of Canadian research institutions will foster the future of knowledge mobilization and research impact. URL: https://resources.researchimpact.ca/resources/activeengagement-of-canadian-research-institutions-will-foster-the-future-of-knowledge-mobilization-and-research-impact [June 12, 2021].

Maslove, David, M. (2018). Medical preprints: A debate worth having. JAMA, 2319(5), 443-444. doi:10.1001/jama.2017.17566

Mowery, David C., Nelson, Richard R., Sampat, Bhaven N., \& Ziedonis, Arvids A. (2001). The growth of patenting and licensing by U.S. universities: An assessment of the effects of the Bayh-Dole act of 1980. Research Policy, 30(1), 99-119. doi:10.1016/S0048-7333(99)00100-6

Bayley, Julie, Phipps, David, Roche, Tony, \& Lodge, Steve. (2021). Reflections and Conjectures Open Scholarly Publishing and Knowledge Mobilization: Combining Two Initiatives to Achieve Social Impact. Scholarly and Research Communication, 12(1). doi:10.22230/src.2021v12n1a391 
Nutley, Sandra M., Walter, Isobel, \& Davies, Huw T.O. (2007). Using evidence: How research can inform public services. Bristol, UK: Policy Press.

OSI. (2019). OSI Infographic 3, 2019: Who does research? Understanding Global Research and Development. URL: https://secureservercdn.net/198.71.233.65/i81.b11.myftpupload.com/wpcontent/uploads/2021/03/OSI-Infographic-3.1.pdf [June 12, 2021].

Pooley, Jefferson. (2020). Read-and-publish open access deals are heightening global inequalities in access to publication. URL: https://blogs.lse.ac.uk/impactofsocialsciences/2020/02/21/read-andpublish-open-access-deals-are-heightening-global-inequalities-in-access-to-publication/ [May 24, 2021].

Powell, Alison, Davies, Huw, \& Nutley, Sandra. (2017). Missing in action? The role of the knowledge mobilisation literature in developing knowledge mobilisation practices. Evidence \& Policy, 13(2), 201-223. doi:10.1332/174426416X14534671325644

Research Excellence Framework. (2020). What is the REF? URL: https://ref.ac.uk/about/what-is-the -ref/ [June 12, 2021].

Reed, Maureen, Robson, James, Lindgren, Amanda, Friedrichsen, Peter, Brock, Tegan, Davidson-Hunt, Ian, Lichtenstein, Gabriela, Shackleton, Sheona, Vassuer, Liette, \& Worthen, Holly. (2020). Foundational principles for intercultural and international research with indigenous and rural peoples: Connecting principles to knowledge mobilization. In Imagining the Futures of Knowledge Mobilization: Perspectives from UNESCO Chairs (pp. 31-50). URL: https://en.ccunesco.ca/-/media /Files/Unesco/Resources/2021/01/ImaginingFutureOfKnowledgeMobilization.pdf [June 12, 2021].

Smith, Katherine E., Bandola-Gill, Justyna, Meer, Nasar, Stewart, Ellen, \& Watermeyer, Richard. (2020). The impact agenda: Controversies, consequences and challenges. Bristol, UK: Policy Press.

Suber, Peter. (2004). Open access overview: Focusing on open access to peer-reviewed research articles and their preprints. Richmond, IN: Earlham College. URL: http://legacy.earlham.edu/ peters/fos loverview.htm [March 26, 2021].

Taylor \& Francis Group. (2019). Taylor \& Francis researcher survey. Milton Park, UK: Taylor \& Francis. URL: https://authorservices.taylorandfrancis.com/wp-content/uploads/2019/10/Taylorand-Francis-researcher-survey-2019.pdf [June 12, 2021].

Tennant, Jonathan P., Waldner, François W., Jacques, Damien C., Masuzzo, Paola, Collister, Lauren B., \& Hartgerink, Chris H.J. (2016). The academic, economic and societal impacts of open access: An evidence-based review. F10oo Research, 5(632), 1-55. doi:10.12688/f10ooresearch.8460.3

United Nations. (2020). SDG publishers compact. URL: https://www.un.org/sustainabledevelopment /sdg-publishers-compact/ [June 12, 2021].

Wiley. (2017). Wiley Open Science Researcher Survey 2016. Figshare. Dataset. doi:10.6084/m9.figshare .4748332 .

Williams, Kate, \& Grant, Jonathan. (2018). A comparative review of how the policy and procedures to assess research impact evolved in Australia and the UK. Research Evaluation, 27(2), 93-105.

doi:10.1093/reseval/rvx042

Wilsdon, James, Bar-Ilan, Judit, Frodeman, Robert, Lex, Elisabeth, Peters, Isabella, \& Wouters, Paul. (2017). Next-generation metrics: Responsible metrics and evaluation for open science. European Commission. URL: http://eprints.whiterose.ac.uk/113919/ [June 12, 2021].

Wróblewska, Marta, N. (2021) Research impact evaluation and academic discourse. Humanities and Social Sciences Communications, 8(58), 1-12. doi:10.1057/s41599-021-00727-8
Scholarly and Research

Communication

VOLUME 12 / ISSUE 1 / 2021

Bayley, Julie, Phipps, David, Roche, Tony, \& Lodge, Steve. (2021). Reflections and Conjectures 